\title{
Nanotecnologías: una revolución tecnológica ad portas en el siglo XXI
}

\section{Alicia Almeida Cantoni*}

\section{"No puedo cambiar la dirección del viento, pero si ajustar mis velas para llegar siempre a mi destino". James Dean}

\section{Resumen}

Este texto se inscribe en una propuesta de análisis y clarificación de la noción de la nanotecnología desde la perspectiva de un estudio de la práctica cientifica. A su vez, este articulo pretende ofrecer un panorama general de los principales problemas y beneficios de las nanotecnologías.

Palabras claves: Nanotecnología, nanociencia, revolución tecnológica.

\section{Abstract}

The framework of this paper is a proposal to analyze and clarify the notion of nanotechnology from the perspective of a study of scientific practice. This article also tries to offer a general view of the main problems and benefits of nanotechnologies.

Key words: Nanotechnology, nanoscience, technological revolution.

La historia de la humanidad permite reconocer al ser humano como un ser de constantes cambios y transformaciones tanto desde el punto de vista individual como colectivo. Esta particularidad se refleja también en el campo del conocimiento científico donde la ciencia al igual que la humanidad se encuentra en un estado permanente de transformaciones. La evolución interna de la ciencia ha dejado como resultado invaluables aportes para el desarro- llo de la humanidad al traer consigo múltiples beneficios para la preservación de la vida en todas sus manifestaciones posibles, no obstante algunos logros de la ciencia y de la tecnología han contribuido a aumentar las posibilidades de que la propia vida se vea en constante amenaza, debido al uso que se hace de este conocimiento.

En las últimas décadas, es posible observar cómo el desarrollo de cierto tipo de tecnologías con un sólido fundamento científico ha producido un impacto enorme a nivel global en el ámbito económico, social y ambiental. Dentro de las tecnologías que han alcanzado un mayor desarrollo se encuentran la nanotecnología y la nanociencia, la biotecnología y la biomedicina, la tecnología y la ciencia de la información, así como diversas tecnologías basadas en las ciencias cognitivas, en especial la neurociencia, entre otras.

La nanotecnología, surgida como resultado de la convergencia de investigaciones en el campo de la química, la biología y la física, es considerada con frecuencia una de las tecnologías con mayor incidencia en el futuro desarrollo de la humanidad. En 1959, Richard Feynman, premio Nóbel de física, propuso elaborar productos con base en el reordenamiento de átomos y moléculas, siendo considerado el padre de la nanociencia. La nanociencia y la nanotecnología han logrado importantes avances en los últimos veinte años, producto de la invención del primer microscopio de barrido con efecto de túnel (STM, en in- 

última década de manera considerable, en el año 2000 dicho gasto fue de 270 millones de dólares, pasando a ser de 464 millones en el 2001 y superando más del millardo de dólares en el $2005^{5}$. En el caso de América Latina los gobiernos que invierten significativamente en el ámbito cientifico y tecnológico son los de Brasil, Argentina y México, no obstante en el campo nanotecnológico estas inversiones se encuentran muy por debajo de lo que deberían para entrar en el proceso de competencia en nanotecnología y tecnología en general, además por encontrarse en paises de la periferia están subordinados o dependen de una manera $\mathrm{u}$ otra de los lineamientos de la Nanored ${ }^{6}$ estadounidense o las redes industriales metropolitanas.

El desarrollo de la nanociencia y las nanotecnologías es inminente, pero ¿cuál es la importancia de este tipo de investigación y desarrollo? y ¿cuáles son los beneficios y peligros que trae consigo esta revolución tecnológica?

La investigación y desarrollo nanotecnológico son importantes, en primer lugar porque la creación de estructuras a escala nanométrica permite controlar las propiedades esenciales de los materiales obteniéndose productos y tecnologías de alta gama. Se considera que la organización de la materia a escala nanométrica es la clave de los sistemas biológicos del futuro, permitiendo obtener nuevos materiales a través del método de auto-organización propio de la naturaleza, que revolucionarán los procesos tecnológicos y por ende la industria. En este nivel atómico no hay diferencia entre la materia biótica y la abiótica, siendo posible aplicar procedimientos biológicos a los procesos materiales y viceversa. En segundo lugar, la nanotecnología se caracteriza por emplear dos métodos generales de tipo teórico y experimental: el top-down (de arriba a abajo), a través del cual es posible acercarse a la precisión necesaria en forma gradual por medio de refinamientos de diferentes tecnologías de fabricación, es decir que otorga la capacidad de controlar en forma precisa y muy bien definida la fabricación de materiales; se construye a partir de la materia tal como está dada por la naturaleza, de acuerdo a sus propias estructuras de unión y se la reduce al tamaño de los objetos de uso. El método bottom-up (de abajo a arriba) hace referencia a la posibilidad de construir un artefacto manipulando la materia a escala nanométrica y ensamblando objetos átomo a átomo, permitiendo la fabricación de materiales

\section{Ibid. p. 168}

"Son principalmente tres actores los que deben intervenir en forma de red: el Estado nación, las unidades económicas privadas (v. gr. multinacionales) y el sistema cientifico tecnológico(v. gr. universidades y centros de Investigación y Desarrollo, tanto públicos como privados) estructurando algunos componentes deliberadamente para que estén en la zona nanométrica (materiales de nanofase). Se trata de construir de lo más pequeño (átomos y moléculas) a lo más grande. En tercer lugar, la nanotecnología combina varias ciencias y tecnologías como la informática, la tecnología de materiales y la biotecnología, entre otras.

Los beneficios de la nanotecnología no son fácilmente cuantificables, pero se estima que en el área de la salud ayudaria a mejorar la calidad de vida y a prolongar la misma, se podrían detectar y combatir enfermedades, como el cáncer, a través de nanosensores incorporados al propio organismo, evitando que se expandan. Nanopartículas de dióxido de titanio se han agregado a algunas lociones y cosméticos del bronceado. Estas partículas minúsculas son transparentes en la piel y pueden absorber además de reflejar rayos ultravioletas. Se podrán fabricar medicamentos específicos y no medicamentos genéricos, donde se tendrán en cuenta las características particulares de la persona. En el área de los materiales, las nanoparticulas inteligentes son quizás el mayor avance, siendo uno de los campos más prometedores el de las prótesis. Constituye evidencia de esto el trabajo de un equipo de científicos argentinos especializados en materiales que desde el 2001 viene estudiando el desarrollo de pequeñísimas partículas y recubrimientos de un nuevo

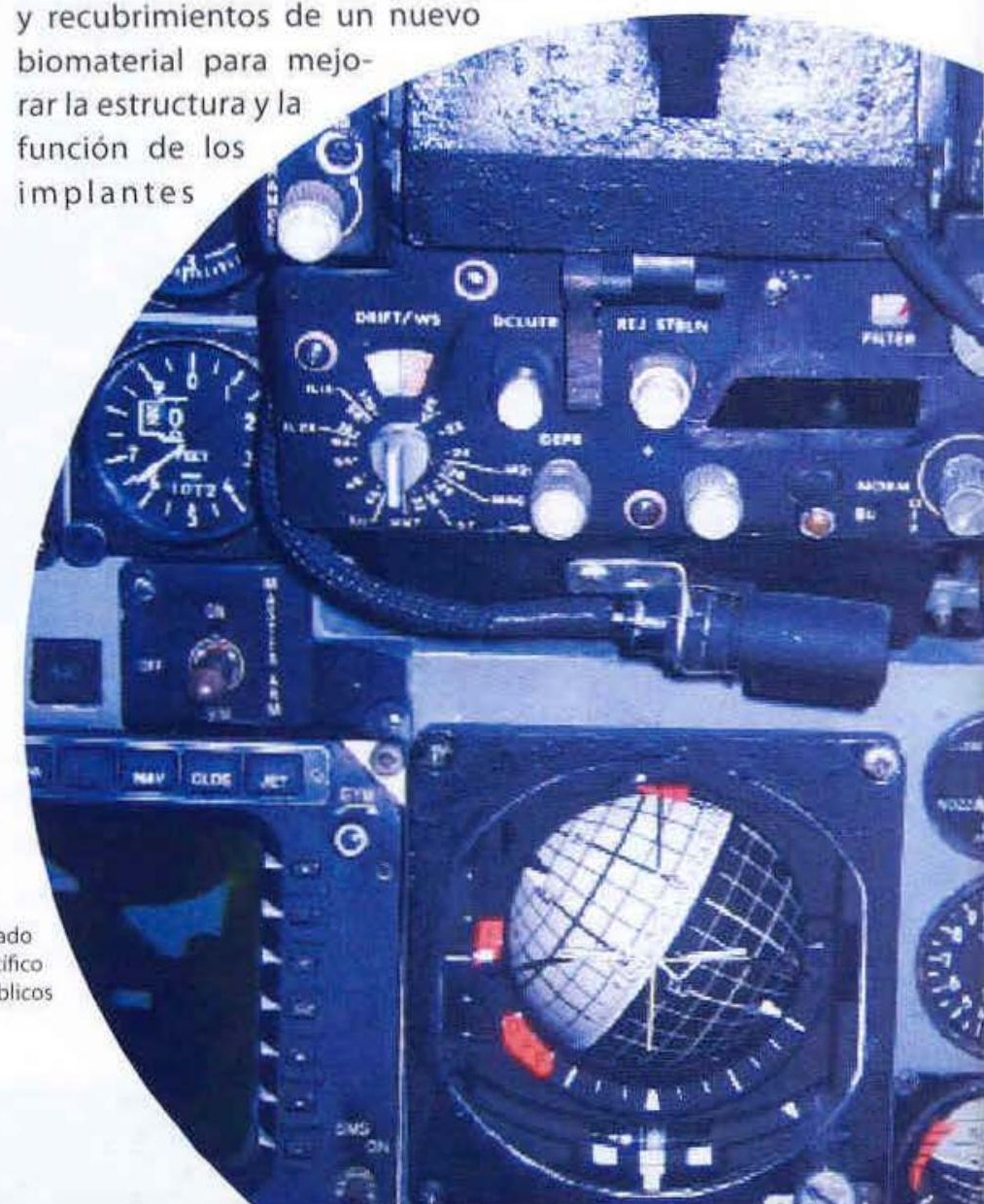


óseos. Este material, creado mediante el uso de nanopartículas fabricadas con técnicas no contaminantes, sería más económico, además de ser una superficie "inteligente", capaz de auto reducir la corrosión del material con los años dentro del organismo, prevenir la adhesión de bacterias al implante, mejorar su integración ósea e inducir la formación del hueso?. Otra aplicación de las nanopartículas se relaciona con la ropa, ésta podrá reaccionar ante los cambios ambientales y mantener la temperatura del cuerpo, repeliendo el sudor y el polvo, sin que exista necesidad de lavarla, o teniendo efectos curativos en caso de accidente (quemaduras, etc.). Las partículas minúsculas del dióxido de titanio, por ejemplo, se pueden acomodar sobre el cristal para hacer ventanas autolimpiadoras - las ventanas rechazan el agua y la luz del sol, analizan la suciedad y permiten que la lluvia limpie el cristal para dejarlo nuevamente prístino. Los materiales como los nanotubos de carbono, notablemente más resistentes que el acero y con un menor peso que éste, son una gran revolución para la industria aeroespacial, la automovilistica y la arquitectura, entre otras. En el área medioambiental se confía en que pequeñas bacterias provistas de sensores puedan consumir cuerpos de agua contaminados por metales pesados o descontaminar en breve tiempo la atmósfera terrestre. En el caso de la agricultura se espera que nanosensores reduzcan el riego y regulen la distribución de nutrientes, beneficiando a muchas regiones del planeta que podrán potabilizar el agua a bajos costos mediante el empleo de nanoproductos.

En relación con los riesgos, peligros o efectos perjudiciales de las nanotecnologías se establece el problema que representan las nanopartículas en el medioambiente y la salud, recientes informes revelan que las nanopartículas pueden ser tóxicas o perjudiciales para la salud cuando entran en contacto con el cuerpo al ser injeridas, inhaladas o inyectadas ${ }^{8}$. Algunas nanopartículas de dióxido de titanio utilizadas en filtros solares causan radicales libres en las células de la piel dañando el ADN. El Dr. Howard ${ }^{9}$ afirma que cuando la partícula es de menor tamaño, mayor es su potencial de toxicidad, las nanoparticulas pueden atravesar las membranas del cuerpo e incluso la barrera de sangre del cerebro. Se estima que las nanopartículas pueden tener distintos efectos sobre el ambiente y la vida tales como entrar en la cadena alimenticia, influenciar la biosfera, alterar los ecosistemas y crear nuevos tipos de

'Diario La Nación, 2007.

'RS\&RAE, 2004.

?wwwietcgroup.org basura. Se considera que el desarrollo de las nanotecnologías traerá una mayor concentración del poder y la riqueza económica, poniendo a los países en desarrollo en una clara desventaja y beneficiando a una pequeña minoría; ya que son las principales compañías multinacionales las que ejercen control sobre la producción, asi como las que financian el desarrollo y la investigación en el campo nanotecnológico.

Finalmente, se puede vislumbrar que esta revolución cientifica traerá grandes avances y transformaciones a escala mundial, siendo importante despertar el interés de los distintos paises y regiones para analizar y determinar las posibles implicaciones éticas, sociales y económicas que ocasionará el desarrollo de la nanociencia y las nanotecnologías en un futuro próximo. En el caso latinoamericano debería reducirse la subordinación o dependencia por medio de la integración regional en materia de Investigación y Desarrollo, de protección de la propiedad intelectual (patentes) y de integración económico-financiera, entre otros.

\section{BIBLIOGRAFIA}

Commission de l'éthique de la science et de la technologie (2007). Ética y nanotecnologia: Dotarse de medios para actuar en http://www.ethique.gouv. qc.ca/Etica-y-nanotecnologia-Dotarse-de.html

Delgado, G.C. (2007). Revista No 27. Sociología política de la nanotecnología en el hemisferio occidental; el caso de Estados Unidos, México, Brasil y Argentina. Tema: Raza y Nación (II). Agosto, p.164181. Universidad de los Andes: Bogotá.

Diario La Nación (2007). Crean un material "inteligente" para implantes óseos. En http://www. lanacion.com.ar/cienciasalud/nota.asp?nota id $=962695 \&$ origen $=$ premium

Roco, M.C. \& Bainbridge (2002). Converging Technologies for Improving Human Performance: Nanotechnology, Biotechnology, Information Technology, and Cognitive Science (NBIC). EUA: National Science Foundation.

RS\&RAE/Royal Society \& The Royal Academy of Engineering (2004). Nanoscience and nanotechnologies. www.royalsoc.ac.uk/policy, www. raeng.org.uk Consultado Noviembre, 2007

Sáenz, T. (2004). Las tecnologías convergentes y la sociedad del conocimiento en http://www.congreso-info. cu/UserFiles/File/Info/Info2006/Ponencias/127.pdf .p.8 